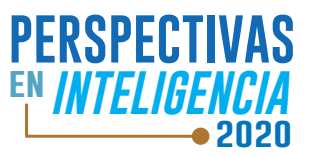

Revista científica en Ciencias Sociales e interdisciplinaria

Bogotá D.C., Colombia

Volumen 12, número 21, enero-diciembre 2020, pp. 151-181

https://doi.org/10.47961/2145194X.223

\title{
Programa lúdico-práctico de inteligencia emocional en preadolescentes del Centro Educativo Rural Bábega, del Municipio de Silos: una estrategia de construcción de paz
}

\author{
Recreational-practical program of emotional intelligence in pre-adolescents of "Babega" \\ Rural Educational Center of the Municipality of Silos: a peacebuilding strategy
}

\author{
Doris Liliana Sánchez Flórez ${ }^{1}$
}

(1) Universidad de Pamplona, Pamplona - Norte de Santander, doris.sanchez@unipamplona.edu.co

\section{Resumen}

El presente artículo parte de un paradigma analítico y un enfoque metodológico mixto con el fin de diseñar un programa lúdico-práctico de inteligencia emocional para preadolescentes del C.E.R Centro Educativo Rural Bábega, del municipio de Santo domingo de Silos, Norte de Santander, como estrategia de construcción de paz. Para ello se buscó determinar el nivel de percepción, facilitación, comprensión y regulación emocional, a partir de tareas de ejecución a través de la aplicación del Test de Habilidad de Inteligencia Emocional en la Escuela (THInEmE) de Isabel María Merchán Romero, Universidad de Extremadura España, 2017. Seguidamente, se propone un programa de inteligencia emocional en preadolescentes del Centro Educativo Rural Bábega como estrategia de Construcción de Paz y, finalmente, se buscó reconocer la construcción de la Paz en el escenario educativo desde la Inteligencia Emocional.

Los resultados de la investigación dan cuenta que aunque los estudiantes se esfuerzan por mantener una actitud reconocedora de sus propias emociones y de las de sus pares externos, aún existen claras debilidades en la forma como perciben, facilitan y regulan dichas emociones para una efectiva toma de decisiones o para el fortalecimiento del autoestima personal, por lo que se hace necesaria la intervención psico-pedagógica a partir de estrategias que no sólo incidan en su aprendizaje emocional, sino en las formas como se construyen escenarios de paz desde las aulas.

Palabras clave: Inteligencia emocional; Paz; Valores; Percepción; Comprensión; Aprendizaje; Regulación; Facilitación.

\section{Abstract}

This article is based on an analytical paradigm and a mixed methodological approach in order to design a playful-practical program of emotional intelligence for preadolescents of the Bábega, Regional Education Center of the municipality of Santo Domingo de Silos Norte de Santander, as a strategy for the construction of peace. For this, it was sought to determine the level of perception, facilitation, understanding and emotional regulation, from execution tasks through the application of the Emotional Intelligence Skill Test at School (THInEmE), then an intelligence program is proposed 
Emotional intelligence in preadolescents from the Bábega Rural Education Center as a Peacebuilding strategy and finally, it was sought to recognize the construction of Peace in the educational scenario from Emotional Intelligence.

The research results show that although students strive to maintain an attitude that recognizes their own emotions and those of their external peers, there are still clear weaknesses in the way they perceive, facilitate and regulate said emotions for an effective decision-making. decisions or for the strengthening of personal self-esteem, which is why psycho-pedagogical intervention is necessary from strategies that not only affect their emotional learning, but also in the ways in which peace scenarios are built from the classrooms.

Keywords: Emotional intelligence; peace; values; perception; understanding; learning; regulation; facilitation.

\section{Introducción}

Las escuelas colombianas han perpetuado el fenómeno de la violencia en el contexto educativo, sumándose a la falta de estrategias y acciones en pro de una cultura de la paz y un aprendizaje emocional, que ha sido poco estudiado y controlado por los entes gubernamentales. Por lo cual, Calderón (2011) declara que, en conductas violentas como el acoso, el matoneo, el mal clima escolar o los conflictos escolares destructivos, "se presenta una biopolítica que es invisible al control de la escuela, pero visible ante los sujetos que interesan en la subordinación, a los sujetos potencialmente dominables" (p.50). Por tanto, los estudiantes destructivos o las personas malintencionadas dirigen su accionar a los blancos más "débiles", en donde la víctima y el victimario tienen poca inteligencia emocional y autoestima.

En efecto, esta investigación pretende diseñar un programa lúdico-práctico de Inteligencia Emocional para preadolescentes del Centro Educativo Rural Bábega, del municipio de Santo Domingo de Silos, Norte de Santander, como estrategia de Construcción de Paz. Para ello, en primera instancia se busca determinar el nivel de percepción, facilitación, comprensión y regulación emocional, a partir de tareas de ejecución a través de la aplicación del Test de Habilidad de Inteligencia Emocional en la Escuela (THInEmE); seguidamente se propone un programa de Inteligencia Emocional en Preadolescentes del Centro Educativo Rural Bábega como estrategia de Construcción de Paz y, finalmente, se pretende reconocer la construcción de la Paz en el escenario educativo desde la Inteligencia.

En este sentido, se busca llevar a cabo una investigación descriptiva con enfoque mixto que permita comprender los niveles de puntuación en inteligencia emocional de estos estudiantes de 11 y 12 años. Los resultados no solo permiten comprender aún más la manera como estos niños y niñas ponen en práctica su inteligencia emocional, sino que destacan la necesidad de implementar estrategias y metodologías que incidan en el componente socioafectivo de los estudiantes a través de propuestas lúdicopedagógicas. 


\section{Marco teórico}

El segundo hogar de la formación de un ser humano es la escuela, en donde puede aprender a autoconocerse, a autorregularse y a mejorar su autoconcepto para convivir mejor con los demás. Sin embargo, pese a su gran relevancia, no se le ha dado la importancia necesaria, tanto que pudiera darse o aplicarse en el currículo educativo como una cátedra o asignatura de educación emocional que permitiera preparar a los estudiantes no solo para producir conceptos y después recursos, sino para que sean seres que se amen a sí mismos, amen a los demás y sean útiles y felices. A partir de esta perspectiva, esta investigación gira en respuesta a la siguiente pregunta orientadora ¿Por qué implementar un programa de Inteligencia Emocional en preadolescentes del Centro Educativo Rural Bábega, del Municipio de Silos, como estrategia de construcción de Paz?

En relación con lo anterior, dentro de las investigaciones previas relacionadas, es importante mencionar al autor Ferragut \& Fierro (2009) con la investigación titulada "Inteligencia emocional, bienestar personal y rendimiento académico en preadolescentes", orientada a analizar la relación entre la inteligencia emocional y el bienestar personal y su posible predicción del rendimiento académico. Este estudio concluye que la educación en valores, el conocimiento de las emociones y el bienestar son aspectos claves para un desarrollo psicológico integral que podrá ayudar a los jóvenes a enfrentarse adecuadamente a la compleja etapa de la adolescencia y que colaborará en la prevención de trastornos del comportamiento y en la promoción de actitudes saludables para la sociedad.

Otra de las investigaciones significativas corresponde a Márquez \& Gaeta (2014), quienes presentan el estudio "Competencias emocionales en los preadolescentes: la implicación de los padres", buscando analizar el nivel de implicación que los padres tienen en el desarrollo de competencias emocionales y en la toma responsable de decisiones de sus hijos preadolescentes. Los autores de la investigación reafirman la importancia de trabajar las competencias emocionales y la toma responsable de decisiones en los preadolescentes a partir de la IE en el seno familiar, que pudiera prevenir que los estudiantes caigan en situaciones de riesgo que afecten su salud mental y física, concluyendo que la forma en que los niños y preadolescentes muestran sus emociones viene determinada por lo que ven en los adultos que los rodean.

En lo que se refiere al marco teórico, este trabajo investigativo se guía desde las concepciones de cuatro ejes temáticos principales: Inteligencia emocional, Paz, Educación, Psicología de la conducta agresiva y desarrollo de la Adolescencia; así mismo, de estos ejes se desprende una subdivisión temática que fundamenta el objetivo principal de la presente investigación, la cual se expone a manera de resumen, destacando los aspectos más importantes a continuación: 


\section{Modelos Teóricos de la Inteligencia Emocional}

Modelo Inteligencias Múltiples de Gardner: Gardner (1993, citado en Mejía, 2012) sustentó las inteligencias múltiples, en que aborda aspectos como: inteligencia naturalista, lógico-matemática, intrapersonal-interpersonal, kinestésica, musical, espacial y lingüística; así mismo, Gardner se presenta para muchos como el precursor de la inteligencia emocional, ya que para él esta se define dentro de la inteligencia intrapersonal y la interpersonal, que "facilita la compresión de las propias emociones y las de los demás, contribuyendo a la regulación de los propios sentimientos" (p. 14).

Modelo mixto de Inteligencia Emocional de Goleman: Desde el modelo de la inteligencia emocional de Goleman (1995, como se citó en García y Giménez, 2010) se proponen cinco aspectos:1). Conciencia de uno mismo: Es la conciencia que se tiene de los propios estados internos, los recursos e intuiciones. 2). Autorregulación: Es el control de nuestros estados, impulsos y recursos internos. 3). Motivación. Se explican como tendencias emocionales que guían o que facilitan el logro de objetivos. 4). Empatía: Se entiende como la conciencia de los sentimientos, necesidades y preocupaciones ajenas.5). Habilidades sociales: Es la capacidad para inducir respuestas deseables en los demás, pero no entendidas como capacidades de control sobre otro individuo. (p. 46). Para Roca (2013), las habilidades sociales son definidas como el "Conjunto de hábitos en nuestras conductas, pero también en nuestros pensamientos y emociones que nos permiten comunicarnos con los demás en forma eficaz, mantener relaciones interpersonales satisfactorias, sentirnos bien al relacionarnos con otras personas y conseguir que los demás no nos impidan lograr nuestros objetivos" (p.2).

Modelo de Bar-On: El modelo de Bar-On (1997), el cual de la misma forma que el modelo Goleman (1995, como se citó en Zavala, Valadez y Vargas, 2008) define la inteligencia emocional como: "Un conjunto de capacidades emocionales personales e interpersonales que influyen en la capacidad global del individual para afrontar las demandas y presiones del medio ambiente", Bar-On (1997, como se citó en Roca, 2013, p.1). Por ende, el modelo de Bar-On (1997, citado en García y Giménez, 2010) fue expuesto como inteligencia emocional-social, el cual comprende seis componentes: intrapersonal, interpersonal, estado de ánimo en general, adaptabilidad, manejo del estrés y estado de ánimo en general (p.47).

Modelo de Habilidades Mentales (I.E) De Mayer y Salovey: Posteriormente a los modelos mixtos de la inteligencia emocional se proyectó uno de los paradigmas más importantes para esta teoría, el cual fue sustentado por Mayer y Salovey (1997, como se citó en Trujillo y Rivas, 2005): "Su modelo se denomina Trait Meta-Mood Scale (TMMS) y hace parte de los modelos de habilidades mentales, los cuales se enfocan principalmente en el contexto emocional de la información y el estudio de las capacidades relacionadas con dicho procesamiento" (p.8). De esta forma, tomando como referencia el modelo de habilidades mentales, Mayer y Salovey (1997, como se citó en Fernández y Extremera, 2005) definen la IE de la siguiente manera: "Es la habilidad para percibir, valorar y expresar emociones con exactitud, la habilidad para acceder y/o generar sentimientos que faciliten el pensamiento; la habilidad para comprender emociones y el conocimiento emocional y la habilidad para regular las emociones promoviendo un crecimiento emocional e intelectual" (p. 68). De acuerdo con lo anterior, este modelo se encarga de explicar el procesamiento de las emociones de manera cognitiva y, a diferencia de los modelos mixtos, esta se enfoca principalmente 
en procesos internos/cognitivos que conllevan a la adaptabilidad y el manejo de la inteligencia emocional en los distintos contextos.

Modelo de Fernández y Extremera: Extremera y Fernández (2001 como se citó en Trujillo y Rivas, 2005.p.10) plantean un modelo que consta de tres componentes correspondientes a percepción (capacidad de sentir y expresar sentimientos adecuadamente), comprensión (comprensión de los estados emocionales) y regulación (capacidad de regular estados emocionales correctamente).

Modelo de Rafael Bisquerra Alzina: uno de los teóricos modernos que ha contribuido con más investigaciones, respecto a la Inteligencia Emocional, es Rafael Bisquerra Alzina. Este modelo se ha experimentado con éxito en la educación (Bisquerra, 2009), el cual comprende las siguientes competencias: a) La Conciencia Emocional, que consiste en conocer las propias emociones y las emociones de los demás. b) La regulación de las emociones, que significa dar una respuesta apropiada a las emociones que se experimentan. c) La autonomía emocional, que es la capacidad de no verse seriamente afectado por los estímulos del entorno; se trata de tener sensibilidad con invulnerabilidad. d) Las habilidades socioemocionales, que constituyen un conjunto de competencias que facilitan las relaciones interpersonales, en las que las relaciones sociales están entretejidas de emociones.

Inteligencia emocional en la educación: Para muchos, estos autores han demostrado la relevancia que tiene la IE en los contextos educativos, y es que se hace esencial aplicar estos modelos dentro de la enseñanza en las escuelas, además de aquellas metodologías para mejorar el rendimiento académico, debe priorizarse bajo el modelo de educación emocional para el manejo de sus emociones con el fin de reducir las conductas disruptivas y mejorar las relaciones interpersonales, tal como lo expone Fernández y Extremera (2004b): "El desarrollo de la IE parece una tarea necesaria y el contexto escolar se torna el lugar idóneo para fomentar estas habilidades que contribuirán de forma positiva al bienestar personal y social del alumno" (p.13). Así mismo, Bisquerra (2014) define la educación emocional como: "Un proceso educativo, continuo y permanente, que pretende potenciar el desarrollo de las competencias emocionales como elemento esencial del desarrollo humano, con el objeto de capacitarle para la vida y con la finalidad de aumentar el bienestar personal y social" (p.2).

Inteligencia emocional para la paz: La aplicación de la inteligencia emocional es algo imprescindible en la educación para generar espacios de paz. En contraposición a esto, en la sociedad colombiana se ha presentado de manera efímera el abordaje de estas competencias por lo cual se tuvo que promulgar un decreto ley para su enseñanza, correspondiente al Decreto 1038 de la Ley 1732 de mayo de 2015, que reconoce la paz como un concepto de aprendizaje. Muñeton (2017) describe que la paz "se asemeja a una forma de sentir y de vivir, enmarcada en nuestra inteligencia emocional, en nuestras estructuras cerebrales y en nuestro código genético; en la capacidad de reconocernos como somos, y luego ser capaces de reconocernos en el otro" (p.290)

\section{Modelos de Paz}

Existe un extenso entramado teórico sobre la paz viéndose reformulaciones de este concepto, lo que dio lugar a múltiples y diversos significados. Sin embargo, solo algunos de los modelos han permanecido a través del tiempo, tales como: paz 
negativa, paz positiva, paz neutral y modelos emergentes, como paz imperfecta - paz transformadora, que continuación se abordaran de manera puntual.

Paz Negativa: Según Galtung (1985 como se citó en Ramos, 2016a) esta tipología de paz se define como: "la ausencia de violencia expresa, directa, entre dos o más seres humanos" (p.514). Es decir, que este tipo de paz es dado debido a la desaparición de actos violentos de naturaleza física y psicológica individual o grupal; así mismo, Jiménez (2009) hace una interpretación de este concepto, diciendo que "paz negativa debe incluir ausencia de malos tratos, violaciones, abusos de la infancia y matanzas callejeras (violencia directa no organizada)" (p. 151).

Paz Positiva: No solo implica la ausencia de violencia directa, sino que amplía aquellos aspectos concernientes además a la violencia estructural y cultural, lo que conllevó a que el autor planteara tres formas de paz positiva según su tipo de violencia, las cuales son: primero, la paz positiva directa (comprendida como la ausencia de confrontaciones o conductas de agresión), segundo, la paz positiva estructural (representa el cuidado de las necesidades básicas como el alimento, la vivienda, atención médica, educación, buenas relaciones en la comunidad, trabajo digno sin sobreexplotación) y, tercero, la paz positiva cultural o paz neutra (descrita como la conciencia social que justifica y legisla la paz directa y la paz estructural) (Galtung y Lederach, 1985, 2000, como se citaron en Ramos, 2016a, p.516).

Paz Imperfecta: Muñoz (2001 como se citó en Comins, 2002) define la paz como "lo primigenio, lo originario en todas las relaciones humanas. La paz no es vista como lo negativo o contrario a la violencia, sino más bien la violencia como la ausencia de paz" (p.324). Bajo la luz del modelo de Muñoz (2001) se puede comprender la paz como aquel objeto abstracto, el cual hasta cierto punto podría ser manejado por el ser humano, pero que por su naturaleza siempre será inconclusa, presentándose un proceso maleable con pros y contras, comprendiendo así la idea que el autor plantea como constante o lineal, proponiendo que siempre al realizar los procesos relacionados con la paz se tendrán en cuenta sus efectos negativos y positivos, lo que igualmente llevará a su objetivo como lo es establecer el orden en la humanidad.

Paz Transformadora: "Obliga a ocuparse participativa e implicativamente de la paz como objeto de estudio, al ser esta -tanto como el conflicto-, un constructo social en permanente transformación" (Ramos 2015b, p.48). Por lo tanto, se propone el concepto de paz transformadora como aquel proceso que está mediado por las percepciones subjetivas de cada persona, lo que conlleva a establecer juicios de valor, generando violencia o paz.

Construcción de Paz: El término de construcción de paz no fue presentado oficialmente hasta que Boutros Boutros-Ghali (1992, como se citó en Rettberg, 2013) definió la construcción de paz como "Acciones dirigidas a identificar y apoyar estructuras tendientes a fortalecer y solidificar la paz para evitar una recaída al conflicto" (p.16); lo que desde ese entonces llevó a establecer este método como una de las bases primordiales para poder dar fin a los conflictos y mantener el orden entre las sociedades, pero de igual manera haciéndolos parte de esta construcción, teniendo en cuenta las posibles recaídas que podían darse a aquellos tratados. De igual manera, Rettberg, (2013) define la construcción de paz como "Un proceso dinámico, no secuencial, con altibajos y que implica diversos retos y frentes de acción paralelos". (p.17) 
Cultura de Paz: La UNESCO (1999, como se citó en Arango, 2007) la define como el "conjunto de valores, actitudes y comportamientos que reflejan el respeto de la vida, de la persona humana y de su dignidad, de todos los derechos humanos" (p.106). Con lo anterior se infiere que este componente es necesario para fortalecer las bases del mantenimiento de la paz, ya que configura a la comunidad en general a adoptar comportamientos adecuados, valores y principios para la resolución de conflictos de forma pacífica.

\section{Educación}

Para definir el proceso educativo, León (2007) expresa "El hombre debe aprender usando, en principio, los andamiajes de la cultura para adaptarse y transformar su medio y su propia historia individual, necesita aprender lo que no le es innato, y potenciar lo que se le ha dado por herencia genética" (p.596). Por lo tanto, la educación, más que como un ente transmisor de conocimientos, debe tener el objetivo de guiar en esencia a cada persona a su camino de vida, orientar respecto a sus actitudes, capacidades, incluso llegar a cambiar su percepción del mundo, a llegar a integrarlo y hacerlo parte de la sociedad; en pocas palabras, enseñar pautas para su adaptación, su rol y su contribución al mundo. Para ampliar el concepto de educación es necesario resaltar cinco de sus funciones más importantes designadas por Cuadrado (2010), "Transmisión de lo acumulado, Cohesión social, Función compensadora, Reajuste social y Reconstitución democrática".

Educación para la Paz: Desde esta perspectiva se abordan aspectos que incluyen todo lo relacionado con el respeto, las buenas relaciones, la sana convivencia y que más allá de sostener la paz ayudan a establecer el orden social, donde cada persona hace parte y contribuye a la conformación de una cultura que en este caso está enfocada obviamente a la paz; sin embargo, esto se da como una fase inicial desde los contextos educativos, por ende se hace énfasis en esta estructura; para poderlo entender de una mejor manera es necesario verlo desde el punto de vista de Ospina (2010), el cual se refiere a este proceso como: "Un proceso educativo, continuo y permanente, fundamentado en los conceptos de paz positiva y en la perspectiva creativa del conflicto" (p.121).

Pedagogía para la Paz: En primera instancia, Zuluaga y Echeverri (2011, como se citaron en Bejarano, Londoño y Villa, 2016) definen la pedagogía como el "conjunto de nociones y prácticas que hablan del conocimiento, del hombre, del lenguaje de la enseñanza, de la escuela y del maestro, a propósito del acontecimiento de saber: la enseñanza" (p.24). De este modo, la pedagogía para la paz se propone como aquella estrategia sociopolítica que contribuye a la reconstrucción y conformación del tejido social, beneficiando las bases para los posacuerdos y el posconflicto (Giraldo et al. 2018). Las líneas de acción de la pedagogía para la paz, según Ortega y Romero (2018), son educar en la responsabilidad e integrar el contexto como estrategia educativa.

Educación Emocional: En concordancia con este hilo teórico, cabe resaltar la educación emocional como unos de los motores primordiales en pro del desarrollo social y la cultura de paz, ya que este proceso fue diseñado como una estrategia dentro de las instituciones, basado desde la perspectiva teórica de la inteligencia emocional, contribuyendo a la preparación ante las distintas situaciones de la vida que se puedan presentar, por lo cual se dan las herramientas para la regulación y el manejo de las emociones; como consecuencia, uno de los máximos representantes teóricos sobre la 
educación emocional, como lo es Fernández (2010 como se citó en Arcos, Jiménez y Ruiz, 2015), considera que la educación emocional es un "proceso educativo, continuo y permanente que pretende potenciar el desarrollo de competencias emocionales como elemento esencial del desarrollo humano, con objeto de capacitar para la vida y con la finalidad de aumentar el bienestar personal y social" (p.42), afirmando una de las funciones sociales que contiene la educación dentro de su proceso de enseñanza.

\section{Desarrollo y Adolescencia}

La adolescencia es la etapa del ser humano de transición entre la niñez y la adultez en donde el comienzo de la pubertad en la niñez marca el paso a la adolescencia; además, está comprendida desde los 10 hasta los 19 años y se encuentra compuesta por cambios biológicos, psicológicos y sociales. (Organización Mundial de la Salud, 2020). De esta forma, la adolescencia está enmarcada en tres subetapas, las cuales son: la adolescencia temprana, que va desde los 10 a los 13 años; luego la adolescencia media desde, los 14 hasta los 17 años, pasando finalmente a la adolescencia tardía, que abarca de los 18 a los 21 años.

-TABLA 2・ Cambios psicosociales en la adolescencia

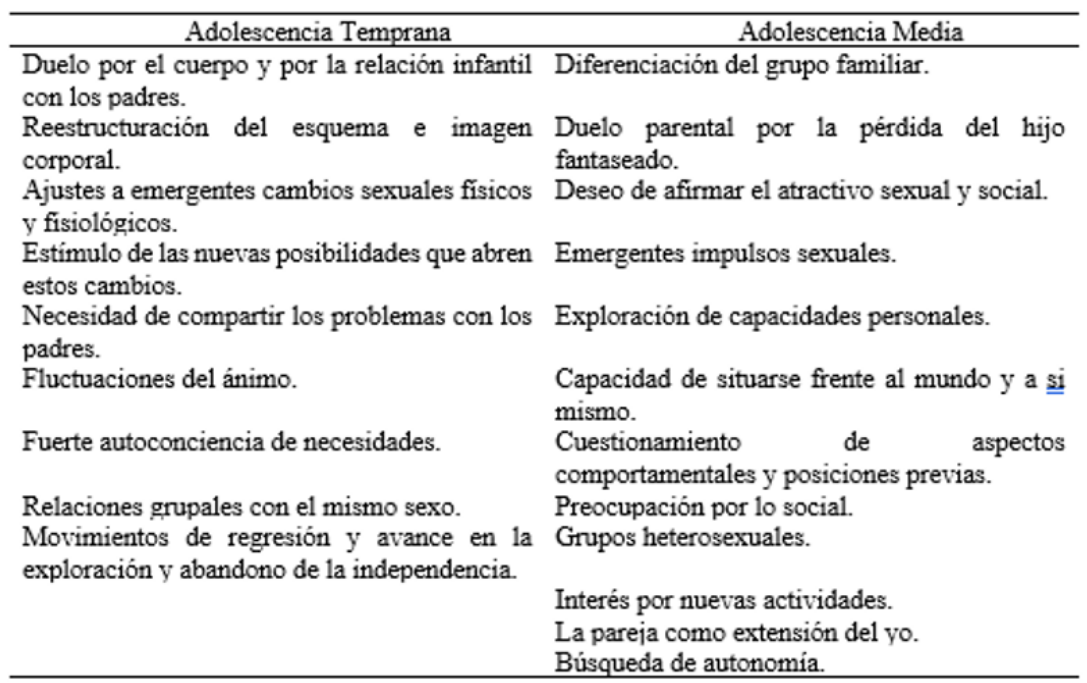

Fuente: adaptado de "El desarrollo psicológico en la adolescencia: las transformaciones en una época de cambios", por D. Krauskopof, 1999, Revista Adolescencia y salud, 1(2). 
Teoría del razonamiento moral del Kohlberg (1969 como se citó en Papalia, 2017), el cual expone tres niveles de razonamiento que se verán a continuación:

Nivel I: Moralidad preconvencional. Las personas actúan bajo controles externos. Obedecen las reglas para evitar el castigo o recibir recompensas, o actúan por su propio interés. Este nivel es típico de los niños de cuatro a 10 años. Nivel II: Moralidad convencional (o moralidad de la conformidad a los roles convencionales). Las personas han internalizado los estándares de las figuras de autoridad. Les preocupa ser "buenas", agradar a los otros y mantener el orden social. Este nivel se alcanza por lo general después de los 10 años; muchas personas nunca la superan, incluso en la adultez. Nivel III: Moralidad posconvencional (o moralidad de los principios morales autónomos). Las personas reconocen conflictos entre los estándares morales y hacen sus propios juicios con base en los principios del bien, la igualdad y la justicia.

Por lo general, este nivel de razonamiento moral solo se alcanza al menos en la adolescencia temprana o más a menudo en la adultez temprana, si es que se logra. (p.343). Haciendo el análisis respectivo de estos tres niveles de razonamiento se puede decir que encasillan perfectamente en la etapa de la adolescencia, ya que al trascender por estos estadios el joven se va desarrollando cognitivamente en razón de la interacción con su medio social como su familia, sus pares, maestros y la comunidad en general que lo rodea; es por esto que, a causa de los dilemas presentados en su cotidianidad, su razonamiento evoluciona y además cabe resaltar que entre más complejidades se presenten en su entorno el ser humano tiende a avanzar de una forma más acelerada hasta llegar al nivel de moralidad posconvencional.

\section{Métodos}

La investigación ha sido desarrollada dentro de un paradigma analítico, de forma que se busca realizar un acercamiento intersubjetivo de la situación problema a partir de una investigación mixta, asociando datos tanto cuantitativos como cualitativos que permitan una comprensión global de la importancia de la inteligencia emocional en la construcción de escenarios de paz desde la escuela. Para el diseño investigativo se lleva a cabo una investigación de tipo descriptiva, de manera que no se pretendió encontrar las causas de la situación problema o establecer una explicación desde el marco causal, sino que se buscó comprender los resultados de los participantes frente a un proceso evaluativo que permitió una comprensión global de su estado actual (en este caso, frente a las dimensiones de inteligencia emocional).

De igual manera, se hizo uso del Diseño de triangulación concurrente (DITRIAC) con el fin de confirmar o corroborar resultados y efectuar validación cruzada entre datos cuantitativos y cualitativos (Hernández, 2014), así como aprovechar las ventajas de cada método y minimizar sus debilidades. La población comprende un total de 195 estudiantes de la sede principal, matriculados entre los grados sexto al once de los programas académicos ofertados por el Centro Educativo Rural Bábega. Se llevó a cabo un muestreo de tipo no probabilístico intencionado, por ende, la muestra específica es conformada por un total de 29 estudiantes inscritos en el Grado Sexto del C.E.R Bábega, discriminando así un total de 13 de ellos de género masculino y 16 de género femenino. 
Dentro de las técnicas de recolección y análisis de información se utilizó cono técnica cuantitativa el Test de Habilidad de Inteligencia Emocional en la Escuela (THInEmE), de Isabel María Merchán Romero (2017), de la Universidad de Extremadura, España; este test es un instrumento de evaluación de la Inteligencia Emocional para alumnos de 8 a 12 años, que permite conocer el nivel de percepción, facilitación, comprensión y regulación emocional, a partir de tareas de ejecución, permitiendo así la identificación del alumnado con bajo nivel y que sirva de punto de partida en el diseño de intervenciones para el desarrollo de las competencias emocionales (Merchán, 2017, p.9).

También se hace uso de la técnica de tipo cualitativo "Triangulación de datos": técnica de análisis de datos que se centra en el contrastar visiones o enfoques a partir de los datos recolectados. A través de esta técnica se hace posible analizar y contrastar tres clases de datos: La información que existe sobre la Inteligencia Emocional, según las categorías de la IE de Goleman (autoconciencia emocional, Autorregulación, Motivación, Empatía y Habilidades Sociales y las competencias emocionales, según Rafael Bisquerra (conciencia emocional, regulación de las emociones, autonomía emocional, habilidades socioemocionales y competencias para la vida y el bienestar). Los datos obtenidos en el Test de Habilidad de Inteligencia Emocional en la Escuela (THInEmE) y el aporte personal y profesional que el estudiante maestrante sobre el tema.

\section{Resultados}

Respecto al Test de Habilidad de Inteligencia Emocional en la Escuela (THInEmE) de Merchán Romero (2017), el análisis de datos se realizó en software estadístico SPSS versión 23. Se aplicaron estadísticos descriptivos para analizar el comportamiento de los datos y finalmente se trabaja con pruebas no paramétricas debido a la naturaleza de los datos.

Con base en los resultados presentados (ver figura 1) se concluye que los jóvenes tanto de 11 como 12 años obtuvieron mayores puntajes (26-43 y 25-41 respectivamente) en la dimensión relacionada con la comprensión emocional, seguidos de puntajes en percepción emocional (21-37 y 23-38 respectivamente), luego se encuentra facilitación emocional, siendo mayores los puntajes para los estudiantes de 12 años (16-29), y para 11 años estuvo entre 12-32; finalmente, la dimensión en la que obtuvieron menor puntaje ambos grupos de edades fue en regulación emocional (6-19 y 9-17 respectivamente). De hecho, la figura 1 destaca líneas de tipo horizontal para cada una de las dimensiones evaluadas, de manera que no se encuentran cambios significativos en los promedios obtenidos para cada grupo etario. 
-FIGURA 1• Distribución de los puntajes promedio en cada dimensión según las edades de los estudiantes

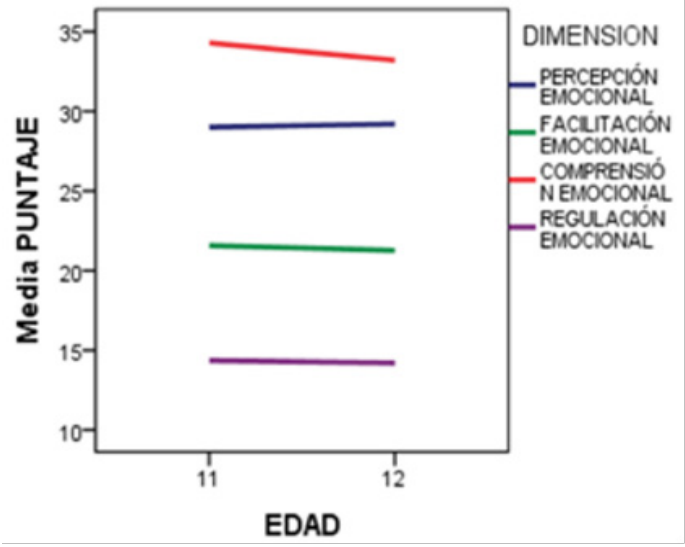

Fuente: elaboración propia

Con respecto al género (ver figura 2) tanto en mujeres como hombres el mayor puntaje se obtuvo en comprensión emocional (26-43 y 25-38 respectivamente, siendo ligeramente mayor el puntaje de las niñas), seguido de percepción emocional (21-36 y 22-38, siendo un poco mayor la puntuación para los niños); luego se encuentra facilitación emocional (12-32 y 16-27 respectivamente, siendo mayores los puntajes para los hombres). Finalmente, la dimensión regulación emocional (6-19 y 9-19). Se generaliza que tanto para género como para edad las dimensiones comprensión emocional y regulación emocional han sido opuestas en cuanto a los puntajes; para la primera se han obtenido puntajes mayores y lo contrario para la segunda. La figura 2 permite concluir que no se encuentran diferencias significativas en los puntajes promedio del género en cada una de las dimensiones. En la línea relacionada con percepción emocional se aprecia una diferencia de 4 puntos, siendo mayor el promedio en niños.

-Figura 2• Distribución de los puntajes promedio en cada dimensión según el género de los participantes

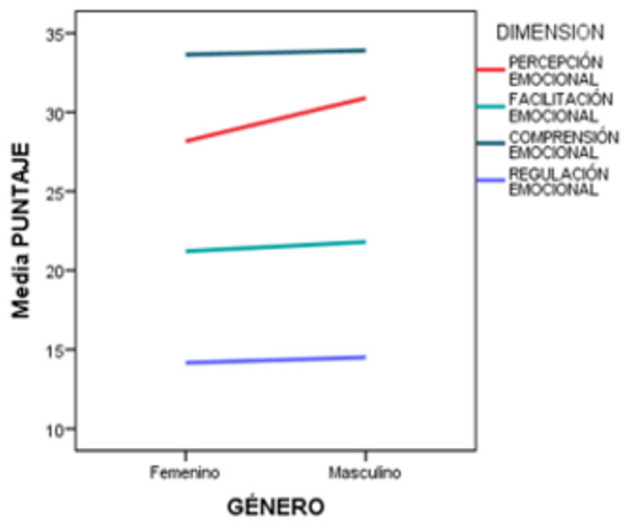

Fuente: elaboración propia 
Entre los resultados también se establece que el puntaje promedio total en inteligencia emocional para las niñas es de 97,16 (con un intervalo de confianza del 95\% que oscila entre 92,20 y 102,11) con desviación estándar de 10,281; mientras que para los niños es de 101,10 (con un intervalo de confianza del 95\% que oscila entre 91,89 y 110,31) con desviación de 12,87, ello indica en ambos casos que existe homogeneidad en las puntuaciones de los estudiantes, aun cuando son más homogéneas las puntuaciones en las niñas. Los puntajes mínimos para niñas y niños son de 78 en ambos casos, mientras que el máximo fue de 120 y 117 respectivamente.

Se determina que el puntaje promedio total en inteligencia emocional para los estudiantes de 11 años es de 99,21 (con un intervalo de confianza del 95\% que oscila entre 91,38 y 107,05) con desviación estándar de 13,566; mientras que para quienes tienen 12 años es de 97,87 (con un intervalo de confianza del 95\% que oscila entre 92,98 y 102,75) con desviación de 8,823, ello indica en ambos casos que existe homogeneidad en las puntuaciones de los estudiantes aun cuando son más homogéneas las puntuaciones para los estudiantes de 12 años. En la tabla 1 y 2 se presentan los resultados para las pruebas de normalidad, estas se aplican con el objeto de identificar si los resultados de las puntuaciones se ajustan a un modelo de distribución normal.

-TABLA 1• Prueba de normalidad por género

\begin{tabular}{|c|l|l|l|l|l|l|}
\hline \multirow{2}{*}{ GÉNERO } & \multicolumn{2}{|l|}{ Kolmogorov-Smimov $^{\mathrm{a}}$} & \multicolumn{2}{l|}{ Shapiro-Wilk } \\
\cline { 2 - 8 } & Estadístico & $\mathrm{gl}$ & Sig. & Estadístico & $\mathrm{gl}$ & Sig. \\
\hline IE TOTAL Femenino & 113 & 19 &, $200^{*}$ &, 974 & 19 &, 853 \\
Masculino & 160 & 10 &, $200^{*}$ &, 939 & 10 &, 545 \\
\hline
\end{tabular}

*. Esto es un límite inferior de la significación verdadera.

a. Corrección de significación de Lilliefors

Fuente: elaboración propia

-TABLA 2・ Prueba de normalidad por edad

\begin{tabular}{|c|c|c|c|c|c|c|c|}
\hline & \multirow[b]{2}{*}{ DAD } & \multicolumn{3}{|c|}{ Kolmogorov-Smirnov a } & \multicolumn{3}{|c|}{ Shapiro-Wilk } \\
\hline & & $\begin{array}{r}\text { Est } \\
\text { adistico }\end{array}$ & $1_{1}^{\mathrm{G}}$ & ig. $S$ & $\begin{array}{r}\text { Est } \\
\text { adístico }\end{array}$ & $1^{\mathrm{g}}$ & ig. $S$ \\
\hline I & &, 09 & 1 & 2 &, 96 & 1 & , \\
\hline & 1 & 2 & 4 & $00^{*}$ & 0 & 4 & 721 \\
\hline TOTAL & &, 18 & 1 &, 1 &, 92 & 1 & , \\
\hline & 2 & 2 & 5 & 96 & 3 & 5 & 217 \\
\hline
\end{tabular}

*. Esto es un límite inferior de la significación verdadera.

a. Corrección de significación de Lilliefors

Fuente: elaboración propia 
Teniendo en cuenta las tablas de los resultados de normalidad y las de estadísticos descriptivos de distribución de la muestra se resume a continuación en la tabla 3 los resultados de los estadísticos respecto a la forma como se distribuyen las puntuaciones totales obtenidas:

-TABLA 3•Valores de la distribución de las muestras según la edad: asimetría, curtosis y ajuste a la normalidad

\begin{tabular}{|l|l|l|l|}
\hline EDAD (Años) & ASIMETRÍA & CURTOSIS & $\begin{array}{l}\text { PRUEBA DE } \\
\text { NORMALIDAD }\end{array}$ \\
\hline 11 & $-0,094$ & $-0,917$ & $\begin{array}{l}\text { P-valor }=0,960 \\
(\text { Sig }=0,721)\end{array}$ \\
\hline 12 & 0,707 & $-0,228$ & $\begin{array}{l}\text { P-valor }=0,923 \\
(\text { Sig }=0,217)\end{array}$ \\
\hline
\end{tabular}

Fuente: elaboración propia

Respecto a la distribución muestral, el índice de asimetría para los estudiantes de 11 años indica una puntuación negativa, de manera que la prueba resulta sencilla para los alumnos.

En cuanto al valor de la curtosis, este no se corresponde a la curva normal en todas las edades, ya que no se sitúa entre - 0,5 y 0,5. Finalmente, la prueba de normalidad, medida con Shapiro-Wilk por cuanto el tamaño de las muestras no supera las 50 observaciones, indica que las distribuciones muestrales en cada una de las edades se identifican con el modelo de la distribución normal.

Respecto a la distribución muestral en la tabla 4, el índice de asimetría indica una puntuación negativa para los niños, de manera que la prueba resulta sencilla para ellos.

-TABLA 4- Valores de la distribución de las muestras según el género: asimetría, curtosis y ajuste a la normalidad

\begin{tabular}{|l|l|l|l|}
\hline GÉNERO & ASIMETRÍA & CURTOSIS & $\begin{array}{l}\text { PRUEBA DE } \\
\text { NORMALIDAD }\end{array}$ \\
\hline Femenino & 0,359 & $-0,028$ & $\begin{array}{l}\text { P-valor }=0,974 \\
(\text { Sig }=0,853)\end{array}$ \\
\hline Masculino & $-0,264$ & $-0,555$ & $\begin{array}{l}\text { P-valor }=0,939 \\
(\text { Sig }=0,545)\end{array}$ \\
\hline
\end{tabular}

Fuente: elaboración propia 
En cuanto al valor de la curtosis para las niñas se corresponde a la curva normal, ya que se sitúa entre - 0,5 y 0,5, mientras que para los niños alcanza a superar este intervalo y se aleja de la distribución normal. Finalmente, la prueba de normalidad, medida con Shapiro-Wilk, indica que las distribuciones muestrales en cada una de las edades se identifican con el modelo de la distribución normal.

La figura 3 permite apreciar que no hay diferencias significativas en los puntajes promedio entre niños y niñas en las dimensiones facilitación emocional, comprensión emocional y regulación emocional, y en cuanto a percepción emocional se aplica el test de Levene, concluyendo que los puntajes presentan varianzas iguales, y seguido se aplica el test $\mathrm{t}$-student con niveles de significación del $5 \%$ y $1 \%$ lo que permite concluir que los datos obtenidos dan evidencia para garantizar que no existen diferencias significativas en el puntaje promedio de niños y niñas.

-FIGURA 3• Diagrama de caja de los puntajes según la dimensión y el género

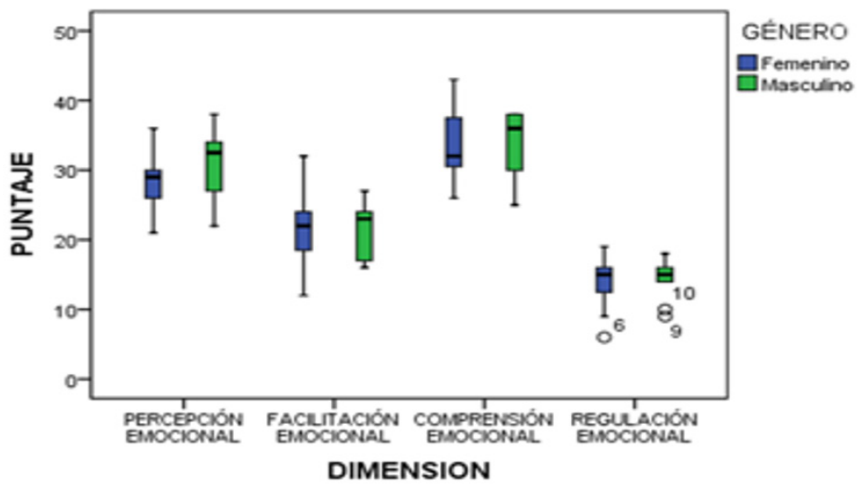

Fuente: elaboración propia

Lo anterior se corrobora con las pruebas que se aplican y detallan a continuación en las tablas 5 y 6 :

-TABLA 5• Comparación entre inteligencia emocional y género

\begin{tabular}{||l|l|l|l|}
\hline GENERO & N & Rango promedio & Suma de rangos \\
\hline Femenino & 19 & 14,05 & 267,00 \\
Masculino & 10 & 16,80 & 168,00 \\
Total & & & \\
& 29 & & \\
\hline
\end{tabular}

Fuente: elaboración propia 
•TABLA 6• Estadísticos de prueba por género

\begin{tabular}{|l|l|}
\hline & IE TOTAL \\
\hline U de Mann-Whitney & 77,000 \\
W de Wilcoxon & 267,000 \\
\hline Sig. asintótica (bilateral) &,- 827 \\
Significación exacta [2*(sig. \\
unilateral)]
\end{tabular}

a. Variable de agrupación: GÉNERO

b. No corregido para empates.

Fuente: elaboración propia

Al comparar el puntaje promedio de inteligencia emocional total en función del género de los estudiantes (tabla 6), al ser $\mathrm{p}$-valor=0,408 mayor al nivel de significancia de la prueba $(\alpha=0,05)$ indica que no existen diferencias significativas en los puntajes promedio en los dos grupos.

Al realizar también la comparación de los puntajes promedio de inteligencia emocional total en función de la edad (tabla 7 y 8), de igual manera al ser $p$-valor=0,710 mayor al nivel de significancia de la prueba $(\alpha=0,05)$ indica que no existen diferencias significativas en los puntajes promedio en los dos grupos respecto a la variable considerada.

-TABLA 7• Comparación entre inteligencia emocional y edad

\begin{tabular}{|c|l|l|l|l|}
\hline & EDAD & N & Rango promedio & Suma de rangos \\
\hline IE TOTAL 11 & 14 & 15,61 & 218,50 \\
12 & 15 & 14,43 & 216,50 \\
Total & 29 & & \\
\hline
\end{tabular}

Fuente: elaboración propia 
-TABLA 8・ Estadísticos de prueba por edad

\begin{tabular}{|l|l|}
\hline & IE TOTAL \\
\hline U de Mann-Whitney & 96,500 \\
W de Wilcoxon & 216,500 \\
\hline Sig. asintótica (bilateral) &,- 372 \\
Significación exacta $[2 *($ sig. &, $715^{b}$ \\
\hline unilateral)] & \\
\hline
\end{tabular}

a. Variable de agrupación: EDAD

b. No corregido para empates.

\section{Fuente: elaboración propia}

Seguidamente se pasó a realizar la baremación de los resultados (tabla 9 y 10). Este procedimiento permite que a partir de la puntuación percentil obtenida por un alumno se pueda evaluar su inteligencia emocional en función de su situación respecto al grupo, de modo que si el alumno se sitúa en un percentil 70 indicará que el $69 \%$ de los sujetos se encuentra por debajo de él en el uso de competencias emocionales y únicamente un $29 \%$ se muestra como alumnos más competentes emocionalmente.

•TABLA 9・Baremo para estudiantes de 11 años

\begin{tabular}{|c|c|c|c|c|c|c|c|c|c|c|}
\hline \multicolumn{6}{|l|}{ Niñas } & \multicolumn{5}{|c|}{ Niños } \\
\hline \multirow[b]{2}{*}{ 西 } & \multicolumn{5}{|c|}{ Dimensiones } & \multicolumn{5}{|c|}{ Dimensiones } \\
\hline & PE & FE & $\mathrm{CE}$ & RE & Tota1 & $\mathrm{PE}$ & FE & $\mathrm{CE}$ & RE & Tota1 \\
\hline \multicolumn{11}{|l|}{$\begin{array}{l}>95 \\
\text { Muy alto }\end{array}$} \\
\hline $\begin{array}{l}85-90 \\
\text { Alto }\end{array}$ & & 32 & 43 & & & 37 & 27 & & 18 & \\
\hline $\begin{array}{l}71-84 \\
\text { Medio-Alto }\end{array}$ & 31,0 & 29,0 & 40,5 & 19,0 & 115,0 & 36,4 & 26,8 & 38,0 & 17,6 & 116,6 \\
\hline $\begin{array}{l}\text { 30-70 } \\
\text { Medio }\end{array}$ & 31,0 & 23,0 & 38,0 & 18,0 & 104,0 & 34,6 & 26,2 & 38,0 & 16,4 & 115,4 \\
\hline $\begin{array}{l}\text { 16-29 } \\
\text { Medio-Bajo }\end{array}$ & 26,0 & 19,0 & 30,0 & 11,0 & 90,0 & 26,0 & 20,8 & 31,6 & 14,0 & 94,8 \\
\hline 5-15 Bajo & 23,5 & 12,0 & 27,5 & 7,5 & 82,0 & 22,0 & 16,0 & 30,0 & 10,00 & 78,00 \\
\hline $\begin{array}{l}<5 \text { Muy } \\
\text { bajo }\end{array}$ & 21,0 & 12,0 & 26,0 & 6,0 & 78,0 & 22,0 & 16,0 & 30,0 & 10,00 & 78,00 \\
\hline
\end{tabular}

Fuente: elaboración propia 
•TABLA 10•Baremo para estudiantes de 12 años

\begin{tabular}{|c|c|c|c|c|c|c|c|c|c|c|}
\hline \multicolumn{6}{|l|}{ Niñas } & \multirow{2}{*}{\multicolumn{5}{|c|}{$\begin{array}{l}\text { Niños } \\
\text { Dimensiones }\end{array}$}} \\
\hline \multirow[b]{2}{*}{ 司 } & \multicolumn{5}{|c|}{ Dimensiones } & & & & & \\
\hline & $\mathrm{PE}$ & $\mathrm{FE}$ & $\mathrm{CE}$ & $\mathrm{RE}$ & Tota1 & $\mathrm{PE}$ & $\mathrm{FE}$ & $\mathrm{CE}$ & $\mathrm{RE}$ & Tota1 \\
\hline $\begin{array}{l}>95 \\
\text { Muy alto }\end{array}$ & 36 & 29 & 41 & & & & & & & \\
\hline $\begin{array}{l}85-90 \\
\text { Alto }\end{array}$ & 35,4 & 28,7 & 40,7 & 17 & 109,5 & 38 & & & 17 & \\
\hline $\begin{array}{l}\text { 71-84 Medio- } \\
\text { Alto }\end{array}$ & 32,1 & 27,1 & 39,1 & 16,4 & 106,8 & 37,2 & 24,0 & 38,0 & 16,6 & 114,2 \\
\hline 30-70 Medio & 29,0 & 24,4 & 33,7 & 15,7 & 103,7 & 34,8 & 24,0 & 38,0 & 15,4 & 105,8 \\
\hline $\begin{array}{l}\text { 16-29 Medio- } \\
\text { Bajo }\end{array}$ & 23,8 & 16,7 & 30,0 & 11,3 & 87,7 & 27,2 & 16,8 & 27,4 & 13,0 & 90,8 \\
\hline 5-15 Bajo & 23,7 & 16,7 & 30,0 & 11,3 & 87,7 & 24,0 & 16,0 & 25,0 & 9,0 & 90,0 \\
\hline$<5$ Muy bajo & 23,0 & 16,0 & 30,0 & 10,0 & 87,0 & 24,0 & 16,0 & 25,0 & 9,0 & 90,0 \\
\hline
\end{tabular}

Fuente: elaboración propia

Respecto a la percepción emocional se concluye que del 100\% de mujeres con 11 años se ubica en los niveles medio-alto, medio bajo y muy bajo con porcentajes de 66,$7 ; 22,2 \%$ y 11,1 respectivamente, y del $100 \%$ de los hombres se ubica en niveles alto, medio y bajo con porcentajes de 20, 60 y 20 respectivamente. Entre tanto, para la edad de 12 años, las niñas se ubican en los niveles muy bajos, medio, medio alto y muy alto, con porcentajes de 10, 70, y 10 respectivamente, mientras que los niños están en bajo, medio y alto con porcentajes de 20,60 y 20 respectivamente.

De lo anterior se concluye que la mayoría de las niñas de 11 años se encuentra en un nivel medio-alto y los niños en un nivel medio. Para la edad de 12 años, la mayoría de las niñas se encuentra en nivel medio, pero, aunque en un porcentaje bajo, también se encuentra personal con un nivel muy bajo y otras con nivel muy alto; y sobre los niños, la mayoría se encuentra en nivel medio.

Respecto a la dimensión facilitación emocional, quienes cuentan con 11 años, un 44,4\% de las niñas se ubica en un nivel medio y un $22,2 \%$ en nivel bajo, mientras que un $11,1 \%$ está en nivel alto, otro 11,1 en nivel medio bajo, al igual que $11,1 \%$ en nivel alto. Mientras que $60 \%$ de los niños está en nivel medio y tanto en bajo como en alto se encuentra $20 \%$ en cada nivel. La mayoría de las niñas con 12 años $(60 \%)$ se ubican en nivel medio, $10 \%$ en muy bajo, $20 \%$ en medio-alto y $10 \%$ en muy alto; de otro lado, la gran mayoría de niños (80\%) está en nivel medio-alto y $20 \%$ en medio-bajo.

Por lo tanto, se puede concluir que, respecto a la dimensión facilitación emocional, las niñas de 11 años tienden a ubicarse en niveles medio y bajo, mientras que la mayoría de los niños se ubican en nivel medio. Por su parte, el 60\% de las niñas de 12 años se ubican en nivel medio, mientras que los niños también se encuentran la mayoría en nivel medio, pero en mayor porcentaje (80\%). 
En cuanto a las niñas de 11 años, la mayoría se ubica en nivel medio alto con un 55,6\%, un $22,2 \%$ en medio bajo y en porcentajes iguales a $11,1 \%$ tanto en muy bajo como en alto, mientras que los niños $80 \%$ en medio y $20 \%$ en bajo. Además, las niñas de 12 años el $50 \%$ se encuentra en nivel medio, porcentajes iguales a $20 \%$ tanto en nivel medio-bajo como medio-alto y solo un $10 \%$ en alto; y los niños se encuentra un $80 \%$ en medio-alto y $20 \%$ en nivel bajo.

En general, en esta dimensión la mayoría de las niñas de 11 años se encuentra en nivel medio alto y los niños en nivel medio, mientras que para quienes cuentan con 12 años el mayor porcentaje está en nivel medio para las niñas y para los niños en medio-alto.

Con relación a las niñas de 11 años, el 44,4\% de ellas se ubica en nivel medio, mientras que en porcentajes iguales de $22,2 \%$ están tanto en medio-bajo como en medio-alto, pero también un 11,1 se encuentra en muy bajo; entre tanto, la mayoría de los niños (60\%) se ubica en nivel medio y $20 \%$ en niveles bajo y alto respectivamente. Las niñas con 12 años, la mayoría (60\%) se ubica en nivel medio, 30\% en nivel medio-alto y alto, y $10 \%$ en muy bajo; mientras que los niños $60 \%$ en nivel medio y $20 \%$, tanto para bajo como para alto. En este caso, tanto la mayoría de niñas como la de los niños se ubican en nivel medio para ambos grupos de edad.

$\mathrm{Al}$ analizar las 4 dimensiones, en general se observa que siempre se encuentran niñas en los dos grupos de edad con niveles muy bajos o bajos, mientras que los niños están en medio-bajo o bajo, lo que da cuenta de una pequeña diferencia que indica un mejor nivel para los niños en ambos grupos de edad; aunque también se debe destacar que las niñas de 12 años obtuvieron niveles alto y muy alto en todas dimensiones, específicamente en percepción y facilitación emocional.

De la tabulación del test, de forma general se concluye que, a pesar de que la puntuación fue diferente para cada género, no existe diferencia significativa de los resultados entre niños y niñas. La dimensión que mayor punteó de forma general para niños y niñas fue Comprensión Emocional, ubicando a las niñas con mayor puntaje; y la de menor puntuación fue Regulación Emocional con menor puntaje en las niñas. Las niñas obtuvieron mayor puntaje en Comprensión Emocional. La percepción emocional es más baja en las niñas, la dimensión facilitación emocional es más alta en los niños, la comprensión emocional fue la dimensión más alta y punteó más en los niños y niñas de 11 años; los estudiantes de 11 años tienen mayor inteligencia emocional. En la figura 4 se observa de forma general que, pese a que las puntuaciones de las niñas son más homogéneas, la mayor puntuación en inteligencia emocional la obtuvieron los niños. 
-FIGURA 4• Diagrama de caja de los puntajes totales de inteligencia emocional entre niños y niñas

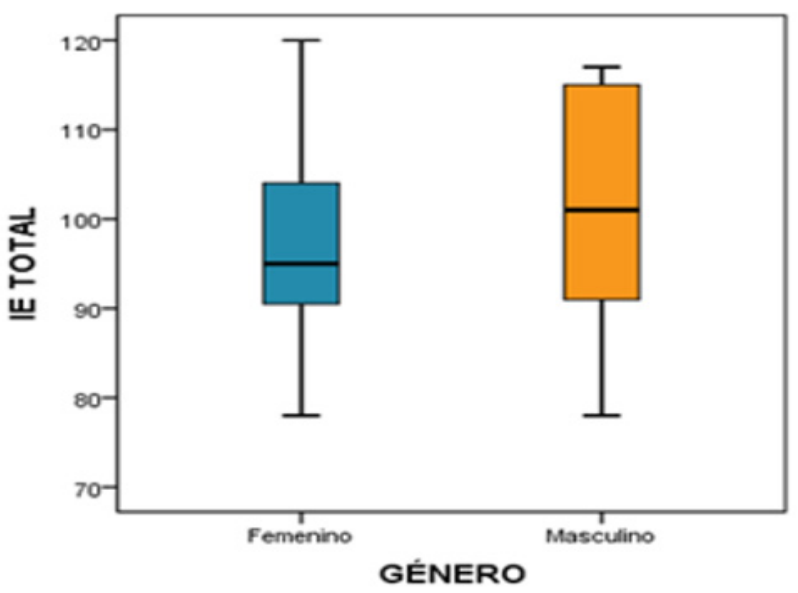

Fuente: elaboración propia

\section{Discusión}

Se busca exponer el proceso de triangulación a partir de la información que existe sobre la Inteligencia Emocional según las categorías de la IE de Goleman (1995) (Autoconciencia emocional, Autorregulación, Motivación, Empatía y Habilidades Sociales y las competencias emocionales); según Bisquerra (2009) (Conciencia emocional, Regulación de las emociones, Autonomía emocional, Habilidades socioemocionales y Competencias para la vida y el bienestar). Los datos obtenidos en el Test de Habilidad de Inteligencia Emocional en la Escuela (THInEmE) son el aporte personal y profesional que el estudiante maestrante haga sobre el tema.

El modelo de habilidad Goleman (1995) define la Inteligencia Emocional-IE como "la habilidad para percibir, valorar y expresar las emociones con exactitud; la habilidad para acceder y generar sentimientos que faciliten el pensamiento; la habilidad para entender la emoción y el conocimiento emocional; y la habilidad para regular las emociones y promover el crecimiento emocional e intelectual" (Mayer y Salovey, 1997, p.10). En efecto, los resultados de la investigación se concentraron en analizar la IE en niños y niñas de 11 y 12 años de un plantel escolar, de forma que para la dimensión Percepción Emocional se encontró que la mayoría de las niñas de 11 años se encuentra en un nivel medio-alto y los niños en un nivel medio de valoración; por su parte, para la edad de 12 años, la mayoría de las niñas se encuentra en nivel medio, pero, aunque en un porcentaje bajo, también se encuentran estudiantes con un nivel muy bajo y otras con nivel muy alto; y respecto a los niños, la mayoría se encuentra en nivel medio.

Ciertamente, encontrar porcentajes de estudiantes en su mayoría ubicados en nivel medio da cuenta de que existen aún limitaciones serias en la valoración y expresión de las emociones de forma auténtica tanto para niños y niñas de 11 y 12 años en general. 
Debilidades en la percepción emocional implica desventajas en el desarrollo social de estos niños, de hecho, Salovey y Mayer (1990, citados por Molero, Saiz y Esteban, 1998) reafirman que la percepción emocional dentro de la IE se configura a partir de la inteligencia social que engloba la capacidad de controlar las emociones propias y la de los demás, así como de discriminar entre ellas y utilizar la información que se proporcionan para guiar los pensamientos y las acciones (p. 25). Por su parte, a partir de Goleman (1995), se comprende que una poca percepción emocional implica una débil autoconciencia emocional y autorregulación, de manera que pueden presentarse riesgos de mala toma de decisiones frente a situaciones externas que implican atmósferas de alta presión.

Estos resultados también fueron cercanos para la dimensión Facilitación Emocional, en que las niñas de 11 años se ubicaron en niveles medio y bajo, mientras que la mayoría de los niños se ubicaron en nivel medio. Por su parte, el 60\% de las niñas de 12 años se ubicó en nivel medio mientras que los niños se posicionaron, la mayoría, en nivel medio, pero en mayor porcentaje (80\%).

No obstante, se encontró que porcentajes significativos (cercanos al 25\%) de estudiantes de ambas edades permanecían en niveles bajos para esta dimensión. De esta forma, se encuentra que a estos niños y niñas no se les facilita apropiadamente el recuerdo de eventos emotivos que permita una formación de juicios acorde a cómo se sienten y, en función de esos posibles sentimientos, tomar perspectivas diferentes ante situaciones o problemas (Fernández-Berrocal y Extremera, 2002).

Ciertamente, se hace necesario indagar aún más en formas o estrategias que logren incidir no solo en la manera como los estudiantes perciben las emociones, sino en cómo las comprenden para llevar a cabo sus pensamientos, propuestas creativas y en general cualquier acción evocada de estos imaginarios, tanto individuales como colectivos, especialmente porque en lo que respecta al comportamiento social, una mayor inteligencia emocional y facilitación emocional se ha relacionado con una mejor percepción de competencia social y un menor uso de estrategias interpersonales negativas (Brackett, Rivers, Shiffman, Lerner y Salovey, 2006; Lopes et al., 2004).

Al mismo tiempo se encuentra, a partir de Goleman (1995), que los procesos de facilitación emocional responden a procesos de Motivación y Empatía, los cuales son fundamentales en el momento de constituir estudiantes capaces de reconocer las vivencias y debilidades socioafectivas de sus pares externos. Incluso, Bisquerra (2009) aclara que actitudes positivas frente a la vida dependen claramente de las formas como los individuos logran encausar sus emociones dentro de sus pensamientos.

Por otro lado, para la dimensión comprensión emocional, definida "como la capacidad de comprender las emociones de uno mismo y de los demás, para poder comprender las causas subyacentes que nos llevan a sentir tales emociones y en su comprensión, fundamentar correctamente nuestros pensamientos nos conducirá a acciones adecuadas inter- e intra-personales" (Pérez y Castejón, 2006, p. 9), ahí se encontró que la mayoría de las niñas de 11 años se encuentra en nivel medio alto y los niños en nivel medio, mientras que para quienes cuentan con 12 años el mayor porcentaje está en nivel medio para las niñas y para los niños en medio-alto. 
De igual manera, es preocupante el bajo porcentaje de estudiantes que superan el nivel medio en esta dimensión, no solo porque invita a pensar que hace falta aún mucho más entendimiento de las emociones individuales de estos estudiantes, sino que se reconocen faltas en la forma como estos niños y niñas logran responder a las problemáticas sociales y familiares que se puedan presentar en su preadolescencia; de hecho, según Salguero et al (2011), las personas emocionalmente inteligentes no solo poseen una mayor capacidad para percibir, comprender y regular sus emociones, repercutiendo de forma positiva en su bienestar personal, sino que también son capaces de generalizar estas habilidades a las emociones de los demás, favoreciendo de este modo sus relaciones sociales, familiares e íntimas.

Los resultados anteriores se interrelacionan con la dimensión de regulación emocional, en la cual también el 44,4\% de las niñas de 11 años se ubicó en nivel medio, mientras que en porcentajes iguales de $22,2 \%$ se posicionaron tanto en medio-bajo como en medio-alto, pero también un $11,1 \%$ se encontró en muy bajo; entre tanto, la mayoría de los niños (60\%) se ubicó en nivel medio y $20 \%$ en niveles bajo y alto respectivamente. En este caso, tanto la mayoría de niñas como la de los niños se ubicaron en nivel medio para ambos grupos de edad. En consecuencia, puede decirse que los estudiantes exhiben un control emocional y, en general, reconocen algunas de sus emociones; sin embargo, es destacable que estos niños y niñas no logran poner en práctica, todo el tiempo, acciones producto de una toma de decisiones que sea resultado de una buena percepción y regulación emocional.

En consecuencia, se percibe que estos niños y niñas necesitan de un acompañamiento en general, desde los cinco aspectos referenciados por autores como Goleman (1995, como se citó en García y Giménez, 2010), tales como la Conciencia personal, como aquella que se tiene de los propios estados internos, los recursos e intuiciones; la Autorregulación, como el control de los estados, impulsos internos y recursos internos; la Motivación, como tendencias emocionales que guían o que facilitan el logro de objetivos; la Empatía, como la conciencia de los sentimientos, necesidades y preocupaciones ajenas y, finalmente, sobre las habilidades sociales, como "la capacidad para inducir respuestas deseables en los demás, pero no entendidas como capacidades de control sobre otro individuo"(p. 46).

Verdaderamente que estos niños, estén felices o tristes, enfadados o eufóricos o desarrollen o no un uso apropiado de su Inteligencia Emocional para regular y comprender sus emociones determina en gran sentido el resultado final de sus desempeños escolares y eventualidades futuras, como su posterior dedicación profesional (Fernández-Berrocal y Extremera, 2002, p. 4). De hecho, Bisquerra (2009) destaca que son las habilidades para la vida una variable dependiente de las formas como los individuos hacen reconocimiento de las emociones propias y ajenas, ya que el juicio depende de la forma como las emociones logran controlarse en procesos mentales equilibrados.

Se trata, entonces, de cuatro conjuntos de habilidades diferentes entrelazadas: la percepción emocional, la facilitación emocional, la comprensión emocional y la regulación emocional, las cuales se establecen de forma jerárquica (Mayer y Salovey, 1997); además, también corresponden con las dimensiones propuestas por Goleman 
(1995) y Bisquerra (2009) en este caso; la primera de las habilidades, es decir, la percepción emocional, supone el nivel basal de esta jerarquía, de menor complejidad, aunque necesaria para permitir las habilidades de tipo superiores, mientras que la habilidad de mayor nivel, o la regulación emocional, se concibe como mayor complejidad, aunque para llegar a ella se necesita un alto dominio de las habilidades anteriores.

En este sentido, al analizar los resultados sobre las cuatro dimensiones en general, se observa que siempre se encuentran niñas en los dos grupos de edad con niveles muy bajos o bajos, mientras que los niños están en medio-bajo o bajo, lo que da cuenta de una pequeña diferencia que indica un mejor nivel para los niños en ambos grupos de edad; aunque también se debe destacar que las niñas de 12 años obtuvieron niveles alto y muy alto en todas las dimensiones, específicamente en percepción y facilitación emocional.

No obstante, los resultados estadísticos permiten inferir que no existen diferencias significativas entre ambos grupos etarios, por cuanto vale la pena decir que se exhiben comportamientos casi homogéneos para la categoría inteligencia emocional en estos niños y niñas; sin embargo, es notable que existen porcentajes preocupantes de niños y niñas de ambas edades ubicados en niveles muy bajos para las dimensiones de IE evaluadas, lo que debe ser puesto en consideración, ya que la habilidad para detectar y comprender las señales emocionales ajenas se presenta como un requisito importante a la hora de determinar un comportamiento social competente (Izard, 2001).

De este modo, aunque la capacidad para "leer" emociones en los rostros de otras personas es uno de los atributos que todos los seres humanos ponen en práctica socialmente, a través de diversas culturas (Ekman, 2003), existen diferencias importantes en el grado en las personas que son capaces de poner en marcha esta habilidad. Por lo que los resultados de la investigación dan cuenta incluso que la dimensión en la que mayor se punteó de forma general para niños y niñas fue Comprensión Emocional, ubicando a las niñas con mayor puntaje; y la de menor puntuación fue Regulación Emocional, con menor puntaje en las niñas, de manera que la capacidad para percibir con precisión las emociones de cada uno está relacionada con la capacidad para evaluarlas en los demás (Zuckerman, Hall, DeFrank y Rosenthal, 1976). En efecto, la comprensión emocional interpersonal se ha relacionado de forma general con un mayor conocimiento emocional y una mejor regulación de las emociones (Extremera, Fernández-Berrocal y Salovey, 2006).

Si bien las estadísticas no mostraron diferencias muy significativas para ambos grupos etarios, se observó de forma general que, pese a que las puntuaciones de las niñas son más homogéneas, la mayor puntuación en inteligencia emocional la obtuvieron los niños, de aquí que autores como Valenzuela \& Portillo (2018) constaten que quienes suelen obtener mejores resultados en el uso y manejo adecuado de sus emociones, tienden a alcanzar un mejor resultado final de sus notas escolares y, en consecuencia, lograr aumentar su rendimiento académico.

No obstante, no se trata de afirmar que por estas razones a los niños les debería ir mejor en el desempeño escolar, sino que existen más razones para pensar que los estudiantes con mejores puntuaciones en IE logran hacer mejores tomas de decisiones 
fundamentadas en una buena percepción y regulación emocional; sin embargo, es claro que estas afirmaciones también deben corresponderse con otras categorías no dispuestas en esta investigación como el componente sociofamiliar, el contexto sociodemográfico o la salud mental.

Por último, se corrobora la postura de Fernández-Berrocal y Extremera (2002), en la cual expresan que la inteligencia académica no es, totalmente, suficiente para alcanzar el éxito profesional, sino que se requiere del conocimiento y la regulación de las emociones para que ambas sean puestas a disposición, de manera que resulta conveniente analizar el desarrollo de inteligencia emocional, ya que esta tiene que ver con la capacidad humana de sentir, controlar y modificar estados emocionales en cada individuo y en las demás, por lo que tiene un componente tanto individual como sociocolectivo del cual depende la buena toma de decisiones de cada persona, por lo que en esta inteligencia no se busca oprimir los sentimientos, sino mantenerlos en equilibrio. En este sentido, desde Bisquerra (2009) se entiende que la regulación consiste en un difícil equilibrio entre la represión y el descontrol, de manera que son componentes importantes de la habilidad de autorregulación la tolerancia a la frustración, el manejo de la ira, la capacidad para retrasar gratificaciones, las habilidades de afrontamiento en situaciones de riesgo (inducción al consumo de drogas, violencia, etc.), el desarrollo de la empatía, etc.

Claramente, en dimensiones como la regulación emocional, tanto niños y niñas tuvieron porcentajes significativos en niveles de ponderación medios y bajos; este hecho permite reafirmar dos elementos, el primero tiene que ver con la necesidad de actuar sobre la capacidad de estos estudiantes y reconocer que se actúa movido por el pensamiento e influenciado por las emociones, de forma que es necesario que dichas emociones sean tenidas en cuenta en el razonamiento, en la forma de solucionar problemas, en los juicios y también en la conducta (Pérez y Castejón, 2006).

Para autores como Salguero et al (2011), si las personas que reconocen adecuadamente las emociones en los demás son capaces de generalizar esta habilidad en la vida emocional propia, es posible que se beneficien de la información que los sentimientos aportan permitiendo un adecuado procesamiento de esta.

Indudablemente, se necesita que desde la niñez se comprenda que ver colectivamente las emociones; se trata también de poner en práctica la inteligencia individual. Dicho de otro modo, se necesita, urgentemente, alejar a los niños de la idea que reconocerse y comprenderse a sí mismo no incide sobre cuánto sabemos del mundo y de otros fenómenos o ciencias. De hecho, aunque se encontraron porcentajes altos de estudiantes en niveles altos en percepción emocional, aún es visible cómo coexisten niños y niñas de ambas edades con habilidades mínimas para identificar las emociones en las personas y en sí mismos, además de saber expresarlas adecuadamente con el fin de poder llevar a cabo una comunicación adecuada y, con ello, mejorar en una posterior toma de decisiones en diferentes circunstancias, especialmente, escolares o personales-familiares (Pérez y Castejón, 2006, p. 9).

Para Salguero et al (2011), otra argumentación posible hace referencia al hecho de que la "asociación entre percepción emocional y ajuste personal esté mediada por los propios beneficios sociales que esta habilidad supone". Desde esta perspectiva, 
la percepción emocional pone de relieve un efecto positivo sobre el ajuste social en la niñez y adolescencia algo que, a su vez, repercute en un mayor sentimiento de competencia y una mayor confianza por parte de estos. De esta forma, aunque los resultados mostraron que la edad no fue una variable determinante a la hora de diferenciar los resultados de inteligencia emocional en estos estudiantes, vale la pena destacar que hubo puntuaciones más altas de IE en niños y niñas de 11 años, este hecho reafirma la necesidad de actuar pedagógicamente desde dimensiones tan importantes como la comprensión emocional, puesto que se suele pensar que entre más grandes o cercanos a la adolescencia son los niños, mejor se conocen a sí mismos o que, de forma automática, tomarán mejores decisiones, hecho que puede ser descartado a partir de los resultados mostrados de esta investigación.

Salguero et al (2011) destaca que se debe poner mucha atención a los sentimientos de estudiantes, es decir, a su factor emocional, ya que queda manifiesto que muchos de ellos no pueden expresar lo que sienten adecuadamente, ya sea por desconocimiento, presión social, presión familiar, personalidad, etc. Es decir, sus acciones y toma de decisiones están influenciadas no solo por lo que sienten sino por las circunstancias que experimentan en su diario vivir, hecho que también depende de una buena identificación de estas, de forma que Salguero et al (2011) afirma que, en el caso contrario, "las acciones y decisiones tomadas tendrán efectos negativos en la conducta".

Por consiguiente, según autores como Valenzuela \& Portillo (2018), existen numerosos factores que afectan la forma de ser de la niñez, uno de ellos es el contexto en que habita, ya que las situaciones y experiencias vividas van forjando y absorbiendo su personalidad, de manera que es útil llevar a cabo estrategias que visibilicen aspectos vivenciales o vulnerabilidades concretas en estos niños y niñas para un correcto diseño de un programa de intervención. De hecho, entre las actitudes más notables se presentan "la timidez, inseguridad y miedo, así como prepotencia, agresividad y coraje, las cuales no permiten que los estudiantes se relacionen y comuniquen de forma efectiva" (Valenzuela \& Portillo, 2018).

Sin duda, la escuela es un excelente lugar para el mantenimiento de acciones en pro del fortalecimiento emocional de los estudiantes; sin embargo, durante mucho tiempo se ha subvalorado la dimensión afectiva y emocional en la educación, la cual influye, significativamente, en la conformación de pedagogías que aboguen por la paz, el aprendizaje de tipo colaborativo y cooperativista. Actualmente, la pedagogía para la paz se propone como aquella estrategia en Colombia que contribuye a la reconstrucción y conformación del tejido social, beneficiando las bases para los postacuerdos y al posconflicto; así mismo, cabe resaltar que las personas que componen esta sociedad son los actores principales que promueven el cambio, ya que asumen un rol preponderante con sus ideologías, tipos de pensamiento y sus comportamientos que proyectan el camino hacia la paz; es imperativo que por medio de la memoria social - cultural de los hechos que ocurrieron, esto no vuelva a repetirse (Giraldo et al. 2018).

De igual manera, se puede analizar que la pedagogía para la paz es aquella herramienta por la cual se apuesta a la paz transformadora. Lamentablemente, la importancia de la escuela tradicional se ha centrado en el expediente académico, dicho de otro modo, en las calificaciones y evaluaciones, impidiendo la importancia del estado emocional de niños y niñas dentro de una pedagogía que ponga en consideración la educación 
emocional y para la paz. De manera que, "Si bien el medio ambiente, lo social y lo cultural influyen en el desarrollo de la inteligencia en el sujeto" (Verdugo, García y Portillo, 2014, p. 13), se destaca la importancia de los factores físicos y biológicos como determinantes para el establecimiento de las percepciones emocionales. En este sentido, la labor docente es fundamental para ayudar a niños y niñas a enfrentar la vida con las herramientas necesarias y las estrategias para formar personas competentes desde el componente emocional (Valenzuela \& Portillo, 2018).

Sin duda, ante estos paradigmas es importante que el maestro fomente los objetivos educacionales que promuevan la inteligencia emocional en su práctica de aula. Para ello, el maestro debe acceder a la interdisciplinariedad a través de la contrastación crítica y permanente entre su bagaje teórico y de sentido común, por un lado, y el mundo empírico de la realidad social, por el otro. De este modo, se desarma el docente como sujeto, meramente, laboral, para pasar a un docente crítico y, sobre todo, reflexivo. Caruana (2005) expone que "la competencia emocional básica supone un estado de conciencia sobre nuestras propias emociones; este reconocimiento se constituye como el primer paso para transformarlas, por ello es fundamental desarrollar esta habilidad en el alumno". (p. 72)

En este sentido, dado que la educación tradicional colombiana bajo la Ley 115 de 1994, se basa en una estructura curricular por disciplinas; es posible inferir que aún desde este marco legal se configura un diseño instruccional que procura por la disciplinariedad, definida por Carvajal (2010) como una extrema especialización en aislamiento de otros ámbitos o temáticas. Por consiguiente, no existe educación para la inteligencia emocional o para la sana convivencia, sino un medio de aprendizaje extremadamente laborista y mecanicista. Además, se denota según Ortega y Romero (2018), la llamada Pedagogía Negativa, la cual se refiere a la pasividad que a veces se presenta en la educación con respecto a los problemas sociales, al no impulsar a los estudiantes a generar un pensamiento crítico que abra las puertas al cambio y a la reflexión desde el componente socioafectivo.

Al respecto, autores como Guadarrama (2019) exponen que: Dejar exclusivamente la promoción de la cultura de paz a la educación superior constituye un grave error. Si esta no comienza a cultivarse en el seno de la familia, de las instituciones del barrio y de la sociedad civil, en las que niños y adolescentes se forman, así como también en la escuela primaria y secundaria, puede que sea tarde intentar cultivar estos valores en la edad juvenil. (p.55)

Con base en lo anterior, es importante que desde la educación se empiece a apostar por el desarrollo de estrategias pedagógicas humanistas, encaminadas hacia un enfoque interdisciplinario y afectivo hacia la construcción de escenarios de paz, ya que para autores como Salguero et al (2011) es posible que aquellos adolescentes con mejor habilidad a la hora de identificar cómo se sienten las personas a su alrededor utilicen dicha información no solo para exponer una mayor empatía hacia ellos, o para regular las emociones que sienten, sino también para cambiar su comportamiento y adecuarse mejor a las situaciones sociales, contribuyendo de esta forma a una cultura de paz y respeto que en él prevalece la empatía y la sana convivencia. "Además, en la medida en que la habilidad de percepción emocional ayude a los adolescentes a adaptarse a su entorno social, estos acabarán mostrando menos sentimientos de estrés y tensión en su vida social" (Salguero et al, 2011). 
En definitiva, la evaluación de la inteligencia emocional en estos niños y niñas demostró que hubo pocas variaciones significativas frente a variables como la edad registrada; sin embargo, se encontró un comportamiento más o menos homogéneo en cada una de las dimensiones evaluadas, dejando entrever que la mayoría de estos estudiantes presenta niveles de inteligencia emocional medios. En efecto, aunque hubo participantes ubicados en niveles altos y muy altos, la gran incidencia de niños y niñas en niveles medios, bajos y muy bajos permite poner de relieve la necesidad de diseñar programas y propuestas pedagógicas o lúdico-pedagógicas que aboguen por un mejor entendimiento de las emociones sentidas y percibidas por estos estudiantes, de manera que se abogue por procesos pedagógicos y escolares regidos por la alta autoestima y la construcción de paz. Al respecto, Rettberg, (2013) define esta construcción de paz como un proceso dinámico que viene encausado con altibajos y que implica diversos retos y frentes de acción paralelos.

De esta forma, no solo se busca alejar al estudiante de la idea de que no hace falta aprender desde el componente afectivo-emocional, sino que se necesitan propuestas que dejen claro que aspectos como la percepción, la facilitación, la comprensión y la regulación emocional inciden directamente en la toma de decisiones, el claro juicio, el desempeño académico, la convivencia pacífica y la manera como los niños y niñas reaccionan a situaciones de su ambiente familiar.

\section{Conclusiones}

Se evidencia que la puntuación fue diferente para cada género, pero no existe diferencia significativa de los resultados entre niños y niñas, de manera que la categoría inteligencia emocional es independiente de esta variable durante este estudio, sin embargo, la dimensión que mayor punteó de forma general para niños y niñas fue comprensión emocional, demostrando que, en general, estos estudiantes se esfuerzan por tener claridad sobre lo que sienten y experimentan, con el ánimo de llevar acciones coherentes con estos sentimientos y emociones; sin embargo, fue evidente que aún muchos de estos niños se ubican dentro de los niveles bajo y mediobajo, dejando observar que existe la necesidad de implementar diversas actividades lúdico-pedagógicas que contribuyan al mejoramiento de esta situación.

Por otro lado, la dimensión de menor puntuación fue regulación emocional, con menor puntaje, especialmente, en las niñas, demostrando que hace falta no solo que estos niños y niñas reconozcan las emociones, las comprendan o las perciban, sino que entiendan el funcionamiento de estas dentro de su conducta y toma de decisiones. En efecto, es claro que estos estudiantes se esfuerzan por mantener una actitud de escucha y de comprensión de las emociones personales y ajenas. Sin embargo, es prudente encaminar acciones que orienten la manera como estos estudiantes usan sus propias interpretaciones afectivas dentro de su vida social y personal.

Ciertamente, aunque las niñas obtuvieron mayor puntaje en dimensiones como la comprensión emocional, obtuvieron puntuaciones más bajas en la dimensión percepción emocional para todo el estudio, dejando a la dimensión facilitación emocional como la más alta en los niños. De hecho, se observa de forma general que, pese a que las puntuaciones de las niñas son más homogéneas, la mayor puntuación en inteligencia emocional la obtuvieron los niños. Así mismo, con base en lo anterior, 
es importante que desde la educación se empiece a apostar por el desarrollo de una estrategia lúdico-pedagógica en la población tomada como objeto de estudio, encaminada hacia un enfoque interdisciplinario y afectivo hacia la construcción de escenarios de paz.

Lo anterior permite concluir que tanto niñas como niños obtuvieron comportamientos parecidos en los resultados de la prueba de IE. Sin embargo, es claro que se deben alejar nociones apresuradas que suelen escucharse, tales como que las niñas suelen madurar mucho más rápido que los niños, o que los preadolescentes ya deben tener una comprensión bastante avanzada de su conducta e inteligencia emocional. Ciertamente, es sobre estas edades cuando se deben llevar a cabo estrategias y programas que permitan un entendimiento pleno no solo de los cambios físicos que se están dando corporalmente debido a la pubertad, sino a las modificaciones en el pensamiento desde el plano afectivo y socioemocional.

De hecho, se denotó que niñas y niños de 12 años no puntuaron con la IE más alta, puesto que dimensiones como la comprensión emocional puntearon mejor en los niños y niñas de 11 años y los resultados dejaron ver que, en general, los estudiantes de 11 años tuvieron mayor inteligencia emocional. Lo anterior deja claro que la edad no asegura un desarrollo lineal o progresivo-automático de la inteligencia emocional, de forma que estas dimensiones no constituyen procesos que deban ser relacionados solo con el crecimiento etario del niño o la niña.

En general, es necesario resaltar que al diseñar un programa lúdico-práctico de Inteligencia Emocional para Preadolescentes como estrategia de Construcción de Paz, la escuela podrá posesionarse como un ente mediador de planes académicos que le permiten a los niños y niñas autopercibirse más y de mejor manera, de forma que se promueva la implementación de prácticas que incidan en la inteligencia emocional para lograr estudiantes con mejores tomas de decisiones, con mejor autoestima y más empáticos. En efecto, no solo se trata de apostar por estrategias relacionadas con la percepción, facilitación, comprensión y regulación emocional, sino en un cambio paradigmático que ponga atención al componente humanista y afectivo de una educación pensada para la paz y la sana convivencia.

De este modo, en la medida en la que se logre encausar una educación mucho más reconocedora del niño como un sujeto social que siente y que piensa, será posible cambiar cifras preocupantes tales como bajos desempeños académicos o violencia escolar. Esta investigación no solo concluye que hace falta un trabajo mucho más profundo para reconocer los baches en la inteligencia emocional de estos estudiantes, la falta de fomento del concepto de resiliencia, como una condición para que los niños se fortalezcan emocionalmente hacia el futuro, sino que también expone el impacto positivo que podría generar un programa lúdico-práctico de Inteligencia Emocional para Preadolescentes como estrategia de Construcción de Paz, que desde su transversalidad con cada una de las áreas del conocimiento incida en la forma como estos niños y niñas se descubren a sí mismos como sujetos transformadores de la realidad social de su país. 


\section{Referencias}

Arango, V. (2007). Paz social y Cultura de Paz. Ediciones Panamá Viejo. https://www. corteidh.or.cr/tablas/30445.pdf

Arcos, N., Jiménez, L. y Ruiz, A. (2015). La educación de la inteligencia emocional en la escuela: referentes conceptuales, lineamientos y experiencias pedagógicas [Tesis de pregrado, Universidad Pedagógica Nacional, Bogotá, Colombia]. http:// repository.pedagogica.edu.co/bitstream/handle/20.500.12209/2598/TE18211.pdf? sequence $=1$ \&isAllowed $=y$

Bar-On, R. (1997). Bar-On Emotional Quotient Inventory (EQ-I): Technical manual. Toronto, Canadá.

Bejarano, N., Londoño, J. y Villa, P. Pedagogías para la paz: una propuesta de educación popular por medio del arte, para la formación de los niños y niñas en la paz [Tesis de pregrado, Universidad de Antioquia, Colombia]. http://ayura.udea. edu.co:8080/jspui/bitstream/123456789/2187/1/CA0183_norman_johana_ paulina_pedagogiapaz.pdf

Bisquerra, R. (2014). Educación emocional e interioridad. [Archivo PDF]. https:// online.ucv.es/resolucion/files/Bisquerra-R.-2014.-Educaci\%C3\%B3nemocional-e-interioridad.pdf

Calderón, J (2011) Análisis y vínculos entre matoneo y vida social en Colombia, una mirada a dos instituciones educativas y al sector El Codito. Universidad Nacional de Colombia

Caruana,A.(2005). Programa de Educación Emocional parala Prevención dela violencia. Conselleria de Cultura, Educació i Esport. (1), 1-270. https://convivencia.files. wordpress.com/2008/11/programa_ed-emocional-esocaruana2005270p.pdf

Comins, I. (2002). Reseña de "La paz imperfecta” de Francisco A. Muñoz (ed.). Convergencia Revista de Ciencias Sociales, 9(29), 321-336. https://www.redalyc. org/pdf/105/10502916.pdf

Cuadrado, J. (2010). El sistema educativo: funciones y principios. Innovación y experiencias educativas, Granada, España, 1-9. https://archivos.csif.es/archivos/ andalucia/ensenanza/revistas/csicsif/revista/pdf/Numero_33/JOSE\%20 FELIX_CUADRADO_1.pdf

Fernández, P. y Extremera, N. (2003c). La inteligencia emocional en el contexto educativo: hallazgos científicos de sus efectos en el aula. Revista de educación. 332, 97-116. http://www.educacionyfp.gob.es/dam/jcr:6b5bc679-e550-47d9804e-e86b8f4b4603/re3320611443-pdf.pdf

Fernández, P. y Extremera, N. (2004b). El papel de la inteligencia emocional en el alumnado: evidencias empíricas. Revista Electrónica de Investigación Educativa. 6 (2), 1-17. https://dialnet.unirioja.es/descarga/articulo/1068423.pdf 
Fernández, P. y Extremera, N. (2005a). La Inteligencia Emocional y la educación de las emociones desde el Modelo de Mayer y Salovey. Revista Interuniversitaria de Formación del Profesorado, 19(3), 63-93. https://www.redalyc.org/ pdf/274/27411927005.pdf

Fernández, P. y Ruiz, D. (2008). La inteligencia emocional en la educación. Revista Electrónica de Investigación Psicoeducativa. 6 (2), 421-436. http://www. investigacion-psicopedagogica.org/revista/articulos/15/espannol/Art_15_256. pdf

Ferragut, M.yFierro,A.(2012). Inteligencia emocional, bienestarpersonalyrendimiento académico en preadolescentes. Revista Latinoamericana de Psicología, 44(3), 95104. https://www.redalyc.org/articulo.oa?id=805/80525022008

Galtung, J. (1985). Sobre la paz. Barcelona: Fontamara.

García, M. y Giménez, S. (2010). La inteligencia emocional y sus principales modelos: propuesta de un modelo integrador. Espiral. Cuadernos del Profesorado, 3(6), 43-52. https://doi.org/10.25115/ecp.v3i6.909

Giraldo, L., Ortiz, L., Gaviria, Y., Aristizábal, W., Villegas, J. y Ramírez, C. (2018). Pedagogía Para la Paz Como Estrategia Sociopolítica Para la Consolidación de Tejido Social en Escenarios de Postacuerdo. Revista Academic Journals. 10(4), 951-926. https://www.researchgate.net/publication/326450529_ PEDAGOGIA_PARA_LA_PAZ_COMO_ESTRATEGIA_SOCIOPOLITICA_ PARA_LA_CONSSLIDACION_DE_TEJIDO_SOCIAL_EN_ESCENARIOS_DE_ POSACUERDO

Goleman, D. (1995). La Inteligencia Emocional. Editorial Kairos. http://www.codajic. org/sites/www.codajic.org/files/Inteligencia\%20Emocional\%20\%20Daniel\%20 Goleman.pdf

González Gómez, D., Carrillo-Sierra, S. M (2018). Inteligencia emocional en docentes de primaria. En Carrillo-Sierra, S. M., Sanabria-Herrera, B. Bermúdez-Pirela, V. y Espinosa-Castro, J. F. (Ed.), Actores en la educación: una mirada desde la psicología educativa. (130-152). Barranquilla, Colombia: Ediciones Universidad Simón Bolívar. https://bonga.unisimon.edu.co/bitstream/handle/20.500.12442/2490/ Cap_6_InteligenciaEmocional_DocentesPrimaria.pdf?sequence=9\&isAllowed=y

Guadarrama, P. (2019). La cultura como condición de paz y la paz como condición de cultura en el pensamiento latinoamericano. Revista Internacional de Filosofía y Cultura, 24 (1), 43-66. http://doi.org/10.5281/zenodo.3108661

Hernández, R., Fernández, C. y Baptista, P. (2014). Metodología de la Investigación. McGraw Hill Education. http://observatorio.epacartagena.gov.co/wp-content/ uploads/2017/08/metodologia-de-la-investigacion-sexta-edicion.compressed.pdf 
Jiménez, F. (2009). Hacia un paradigma pacífico: la paz neutra. Convergencia. Revista de Ciencias Sociales. 16, 141-189. https://www.redalyc.org/pdf/105/10512244007. pdf

León, A. (2007). Qué es la educación. Educere, Universidad de los Andes, Venezuela. 11 (39), 595-604. https://www.redalyc.org/pdf/356/35603903.pdf

Márquez, M. y Gaeta, M. (2014). Competencias emocionales en los preadolescentes: la implicación de los padres. Revista iberoamericana de educación. 66, 7588. https://rieoei.org/historico/documentos/rie66a05.pdf https://doi. org/10.35362/rie660379

Mejía, J. (2012). Reseña teórica de la inteligencia emocional: modelos e instrumentos de medición. Revista Científica U. Distrital, 11-32. https://revistas.udistrital. edu.co/ojs/index.php/revcie/article/download/4505/6254/

Muñetón, C. A. (2017). Anatomía, inteligencia emocional y paz. Revista de la Universidad de La Salle. (73), 277-293. https://ciencia.lasalle.edu.co/cgi/ viewcontent.cgi?article $=2121 \&$ context $=$ ruls

Muñoz, F. (2001). La Paz Imperfecta. Universidad de Granada. https://www.ugr. es/ fmunoz/documentos/pimunozespa\%C3\%B1ol.pdf

Organización Mundial de la Salud, (2020). Salud de la madre, el recién nacido, del niño y del adolescente. https://www.who.int/maternal_child_adolescent/topics/ adolescence/dev/es/

Ortega, P. y Romero, E. (2018). La pedagogía de la alteridad como paradigma de la educación para la paz. Teoría de la Educación. Revista Interuniversitaria, 30(1), 95-116. http://dx.doi.org/10.14201/teoredu30195116

Ospina, J. (2010). La educación para la paz como propuesta ético-política de emancipación democrática. Origen, fundamentos y contenidos. Universitas. Revista de filosofía, derecho y política. (11), 93-125. http://universitas.idhbc.es/ n11/11-07.pdf

Ramos, E. (2016a). El proceso de construcción de paz colombiano más allá de la negociación: una propuesta desde la Paz Transformadora y Participativa. Revista Editorial Bonaventuriana, el ágora USB. 16 (2), 359 - 678. http://www.scielo.org. co/pdf/agor/v16n2/v16n2a09.pdf

Rettberg, A. (2013). La construcción de paz bajo la lupa: una revisión de la actividad y de la literatura académica internacional. Estudios Políticos, 42, Instituto de Estudios Políticos, Universidad de Antioquia, 13-36. http://corteidh.or.cr/ tablas/r31409.pdf

Roca, E. (2013). Inteligencia emocional y conceptos afines: autoestima sana y habilidades sociales. Congreso de inteligencia emocional y bienestar [Presentación en papel] Zaragoza, España. https://www.cop.es/colegiados/PV00520/pdf/ IE,\%20AE,\%20HS.\%206p.pdf 
Salguero, José M., \& Fernández-Berrocal, Pablo, \& Ruiz-Aranda, Desireé, \& Castillo, Ruth, \& Palomera, Raquel (2011). Inteligencia emocional y ajuste psicosocial en la adolescencia: El papel de la percepción emocional. European Journal of Education and Psychology, 4(2), 143-152. ISSN: 1888-8992. https://doi. org/10.30552/ejep.v4i2.71

Salovey y Mayer. (1990). Emotional Intelligence. https://doi.org/10.2190/DUGGP24E-52WK-6CDG

Trujillo, M. y Rivas, L. (2005). Orígenes, evolución y modelos de inteligencia emocional. INNOVAR, Revista de Ciencias Administrativas y Sociales, Universidad Nacional de Colombia, 9-24. http://www.scielo.org.co/pdf/inno/v15n25/v15n25a01.pdf.

Valenzuela-Santoyo, Alba del Carmen, \& Portillo-Peñuelas, Samuel Alejandro. (2018). La inteligencia emocional en educación primaria y su relación con el rendimiento académico, Educare [online]. 2018, vol.22, n.3, pp.228-242. ISSN 1409-4258. http://dx.doi.org/10.15359/ree.22-3.11. 